\title{
Investigation of Rotating MHD Viscous Flow and Heat Transfer between Stretching and Porous Surfaces Using Analytical Method
}

\author{
M. Sheikholeslami, ${ }^{1}$ H. R. Ashorynejad, ${ }^{1}$ \\ D. D. Ganji, ${ }^{1}$ and A. Kolahdooz ${ }^{2}$ \\ ${ }^{1}$ Faculty of Mechanical Engineering, Babol University of Technology, Babol, Iran \\ ${ }^{2}$ Faculty of Mechanical Engineering, Eslamic Azad University of Technology, \\ Khomeninishahr Branch, Iran \\ Correspondence should be addressed to A. Kolahdooz, aminkolahdooz@iaukhsh.ac.ir \\ Received 17 May 2011; Accepted 29 July 2011 \\ Academic Editor: Ezzat G. Bakhoum
}

Copyright (c) 2011 M. Sheikholeslami et al. This is an open access article distributed under the Creative Commons Attribution License, which permits unrestricted use, distribution, and reproduction in any medium, provided the original work is properly cited.

Hydromagnetic flow between two horizontal plates in a rotating system, where the lower plate is a stretching sheet and the upper is a porous solid plate, is analyzed. Heat transfer in an electrically conducting fluid bonded by two parallel plates is studied in the presence of viscous dissipation. The equations of conservation of mass and momentum and energy are reduced to a nonlinear ordinary differential equations system. Homotopy perturbation method is used to get complete analytic solution for velocity and temperature profiles. Results show an acceptable agreement between this method results and numerical solution. Also the effects of different parameters are discussed through graphs.

\section{Introduction}

Flow of a viscose fluid over a stretching surface has important applications in polymer industries. For instance, a number of technical processes concerning polymers involve the cooling of continuous strips extruded from a die by drawing them through a quiescent fluid with controlled cooling system, and in the process of drawing, these strips are sometimes stretched.

Glass blowing, continuous casting of metals, and spinning of fibers also involve the flow over a stretching surface. In all these cases, the quality of the final product depends on the rate of heat transfer on the stretching surface.

Dutta et al. [1] studied the temperature field in the flow over a stretching surface subjected to uniform heat flux. Andersson et al. [2] investigated the unsteady two-dimensional non-Newtonian flow of a power-law fluid past a stretching surface. 
Bujurke et al. [3] and Dandapat and Gupta [4] examined the temperature distribution in the steady boundary layers of a second-grade fluid near a stretching surface. P. S. Gupta and A. S. Gupta [5] investigated the heat and mass transfer on a stretching sheet with suction or blowing. Sakiadis [6] firstly studied the boundary layer flow over a stretched surface moving with constant velocity. Erickson et al. [7] extended the work of Sakiadis to include blowing or suction at the stretched sheet surface on a continuous moving surface with constant speed and investigated its effects on the heat and mass transfer in the boundary layer.

In recent years, the effect of magnetic field in different engineering applications such as the cooling of reactors and many metallurgical processes involve the cooling of continuous tiles has been under more considerable attention. Several engineering processes, such as materials manufactured by extrusion processes and heat-treated materials traveling between a feed roll and a wind-up roll on convey belts possess the characteristics of a moving continuous surface, are just some examples of applications which involve the problem discussed above.

Chakrabarti and Gupta [8] studied the MHD flow of Newtonian fluids initially at rest, over a stretching sheet at a different uniform temperature. Vajravelu and Hadjinicolaou [9] made analysis to flows and heat transfer characteristics in an electrically conducting fluid near an isothermal sheet. Heat transfer analysis of MHD fluid over a uniformly stretching sheet was investigated by Chakrabarti and Gupta [10]; In 1983, Borkakoti and Bharali [11] studied the two-dimensional channel flow with heat transfer analysis of a hydromagnetic fluid where the lower plate was a stretching sheet. The flow between two rotating disks has important technical applications such as lubrication. Keeping this fact in mind, Vajravelu and Kumar [12] studied the effect of rotation on the two-dimensional channel flow. They solved the governing equations analytically and numerically. Most of engineering problems, especially some of heat transfer equations, are nonlinear; therefore, some of them are solved using numerical solution, and some are solved using the different analytic method, such as perturbation method, homotopy perturbation method, and variational iteration method introduced by He $[13,14]$.

Perturbation techniques are based on the existence of small or large parameters, the so-called perturbation quantity. Unfortunately, many nonlinear problems in science and engineering do not contain those kinds of perturbation quantities. Therefore, many different methods have recently introduced some ways to eliminate the small parameter. One of the semiexact methods which does not need small parameters is the homotopy perturbation method.

The homotopy perturbation method was proposed first by He in 1998 and was further developed and improved by He [15]. The method yields a very rapid convergence of the solution series in the most of cases. The HPM proved its capability to solve a large class of nonlinear problems efficiently, accurately, and easily with approximations convergency very rapidly to solution. Usually, few iterations lead to high-accuracy solution. Recently, this method is employed for many researches in engineering sciences. He's homotopy perturbation method is applied to obtain approximate analytical solutions for the motion of a spherical particle in a plane couette flow Jalaal et al. [16]. Then Jalaal et al. [17] showed the effectiveness of HPM for unsteady motion of a spherical particle falling in a Newtonian fluid. Ghotbi et al. [18] used HPM to approximate the solution of the ratio-dependent predatorprey system with constant effort prey harvesting. Also homotopy perturbation method was used for solving nonlinear MHD Jeffery Hamel problem by Moghimi et al. [19]. Recently, Ganji et al. studied the steady-state flow of a Hagen-Poiseuille model in a circular pipe and entropy generation due to fluid friction and heat transfer using HPM [20]. 


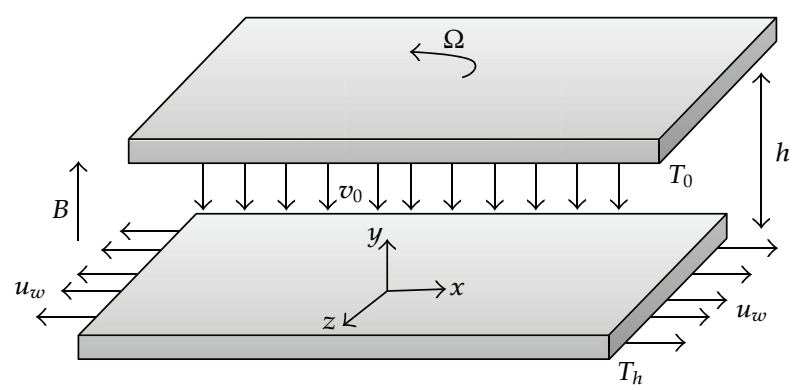

Figure 1: Geometry of the problem.

In this study, the purpose is to solve nonlinear equations through the HPM. It can be seen that this method is strongly capable of solving a large class of coupled and nonlinear differential equations without tangible restriction of sensitivity to the degree of the nonlinear term.

\section{Flow Analysis}

\subsection{Governing Equations}

Consider the steady flow of an electrically conducting fluid between two horizontal parallel plates when the fluid and the plates rotate together around the $y$-axis which is normal to the plates with an angular velocity.

A Cartesian coordinate system is considered as followes: the $x$-axis is along the plate, the $y$-axis is perpendicular to it, and the $z$-axis is normal to the $x y$ plane (see Figure 1 ). The origin is located on the lower plate, and the plates are located at $y=0$ and $y=h$. The lower plate is being stretched by two equal and opposite forces, so that the position of the point $(0,0,0)$ remains unchanged. A uniform magnetic flux with density $B_{0}$ is acting along $y$-axis about which the system is rotating. The upper plate is subjected to a constant flow injection with a velocity $v_{0}$. The governing equations of motion in a rotating frame of reference are

$$
\begin{gathered}
\frac{\partial u}{\partial x}+\frac{\partial v}{\partial y}+\frac{\partial w}{\partial z}=0 \\
u \frac{\partial u}{\partial x}+v \frac{\partial u}{\partial y}+2 \Omega w=-\frac{1}{\rho} \frac{\partial p^{*}}{\partial x}+v\left[\frac{\partial^{2} u}{\partial x^{2}}+\frac{\partial^{2} u}{\partial y^{2}}\right]-\frac{\sigma B_{0}^{2}}{\rho} u \\
u \frac{\partial v}{\partial y}=-\frac{1}{\rho} \frac{\partial p^{*}}{\partial y}+v\left[\frac{\partial^{2} v}{\partial x^{2}}+\frac{\partial^{2} v}{\partial y^{2}}\right] \\
u \frac{\partial w}{\partial x}+v \frac{\partial w}{\partial y}-2 \Omega w=v\left[\frac{\partial^{2} w}{\partial x^{2}}+\frac{\partial^{2} w}{\partial y^{2}}\right]-\frac{\sigma B_{0}^{2}}{\rho} w
\end{gathered}
$$

where $u, v$, and $w$ denote the fluid velocity components along the $x, y$, and $z$ directions, $v$ is the kinematic coefficient of viscosity, $\rho$ is the fluid density, and $p^{*}$ is the modified fluid pressure. The absence of $\partial p^{*} / \partial z$ in (2.4) implies that there is a net cross-flow along the $z$-axis. 
The boundary conditions are

$$
\begin{aligned}
& u=a x, \quad v=0, \quad w=0 \quad \text { at } y=0, \\
& u=0, \quad v=-v_{0}, \quad w=0 \quad \text { at } y=+h \text {. }
\end{aligned}
$$

The following nondimensional variables are introduced:

$$
\eta=\frac{y}{h}, \quad u=a x f^{\prime}(\eta), \quad v=-a h f(\eta), \quad w=\operatorname{axg}(\eta)
$$

where a prime denotes differentiation with respect to $\eta$.

Substituting (2.6) in (2.1)-(2.4), we have

$$
\begin{gathered}
-\frac{1}{\rho h} \frac{\partial p^{*}}{\partial \eta}=a^{2} x\left[f^{\prime}-f f^{\prime \prime}-\frac{f^{\prime \prime \prime}}{R}+\frac{M}{R}+\frac{2 K_{r}}{R} g\right], \\
-\frac{1}{\rho h} \frac{\partial p^{*}}{\partial \eta}=a^{2} h\left[f f^{\prime}+\frac{1}{R} f^{\prime \prime}\right], \\
g^{\prime \prime}-R\left(f^{\prime} g-f g^{\prime}\right)+2 K_{r} f^{\prime}-M g=0,
\end{gathered}
$$

and the nondimensional quantities are defined, in which $R$ is the viscosity parameter, $M$ is the magnetic parameter, and $K_{r}$ is the rotation parameter

$$
R=\frac{a h^{2}}{v}, \quad M=\frac{\sigma B_{0}^{2} h^{2}}{\rho v}, \quad K_{r}=\frac{\Omega h^{2}}{v} .
$$

Equation (2.7) with the help of (2.8) can be written as follows:

$$
f^{\prime \prime \prime}-R\left[f^{\prime^{2}}-f f^{\prime \prime}\right]-2 K_{r}^{2} g-M^{2} f^{\prime}=A .
$$

Differentiation of (2.11) with respect to $\eta$ gives

$$
f^{i v}-R\left(f^{\prime} f^{\prime \prime}-f f^{\prime \prime}\right)-2 K_{r} g^{\prime}-M f^{\prime \prime}=0
$$

Therefore, the governing equations and boundary conditions for this case in nondimensional form are given by

$$
\begin{gathered}
f^{i v}-R\left(f^{\prime} f^{\prime \prime}-f f^{\prime \prime}\right)-2 K_{r} g^{\prime}-M f^{\prime \prime}=0, \\
g^{\prime \prime}-R\left(f^{\prime} g-f g^{\prime}\right)+2 K_{r} f^{\prime}-M g=0,
\end{gathered}
$$


subject to the following boundary conditions:

$$
\begin{gathered}
f=0, \quad f^{\prime}=1, \quad g=0 \quad \text { at } \eta=0, \\
f=\lambda, \quad f^{\prime}=0, \quad g=0 \quad \text { at } \eta=1, \\
\lambda=\frac{v_{0}}{a h} .
\end{gathered}
$$

\section{Heat Transfer Analysis}

\subsection{Energy Equation}

The energy equation for the present problem with viscous dissipation in nondimensional form is given by

$$
\begin{aligned}
u \frac{\partial T}{\partial x}+v \frac{\partial T}{\partial y}+w \frac{\partial T}{\partial z}= & \frac{\bar{k}}{\rho c_{p}}\left(\frac{\partial^{2} T}{\partial x^{2}}+\frac{\partial^{2} T}{\partial y^{2}}+\frac{\partial^{2} T}{\partial z^{2}}\right)+\mu \varphi \\
\phi= & 2\left[\left(\frac{\partial u}{\partial x}\right)^{2}+\left(\frac{\partial v}{\partial y}\right)^{2}+\left(\frac{\partial w}{\partial z}\right)^{2}\right]+\left(\frac{\partial v}{\partial x}+\frac{\partial u}{\partial y}\right)^{2}+\left(\frac{\partial w}{\partial y}+\frac{\partial v}{\partial z}\right)^{2} \\
& +\left(\frac{\partial w}{\partial x}+\frac{\partial u}{\partial z}\right)^{2}-\frac{2}{3}\left(\frac{\partial u}{\partial x}+\frac{\partial v}{\partial y}+\frac{\partial w}{\partial z}\right)^{2}
\end{aligned}
$$

With replacing nondimensional variables and using similarity solution method, by neglecting the last term of viscous dissipation in the energy equation, we have the following energy equation:

$$
\theta^{\prime \prime}+\operatorname{Pr}\left[R f \theta^{\prime}+\operatorname{Ec}\left(4 f^{\prime 2}+g^{2}\right)+\operatorname{Ec}_{x}\left(f^{\prime \prime 2}+g^{\prime 2}\right)\right]=0
$$

subject to the boundary conditions

$$
\theta(0)=1, \quad \theta(1)=0,
$$

where $\operatorname{Pr}=\mu C_{p} / \bar{k}$ is the Prandtl number, Ec $=a^{2} h^{2} / C_{p}\left(\theta_{0}-\theta_{h}\right)$ is the Eckert number, $\mathrm{Ec}_{x}=a^{2} x^{2} / C_{p}\left(\theta_{0}-\theta_{h}\right)$ is the local Eckert number, and the nondimensional temperature is defined as

$$
\theta(\eta)=\frac{T-T_{h}}{T_{0}-T_{h}}
$$

where $T_{0}$ and $T_{h}$ are temperature at the lower and upper plates. 


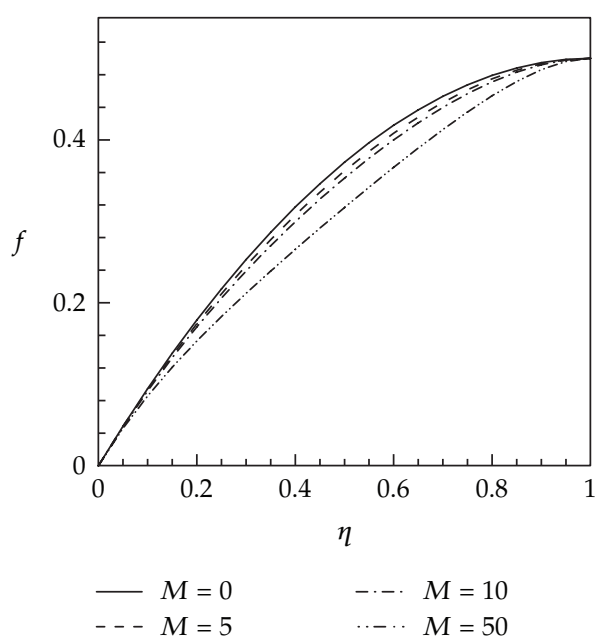

(a)

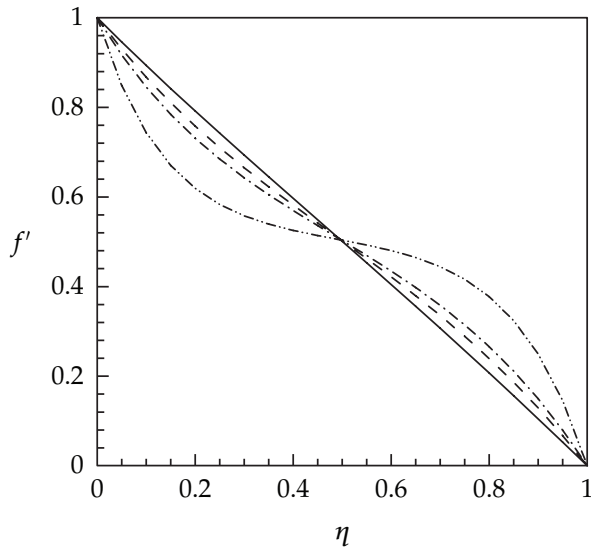

$M=0$
$--M=5$

-.-. $M=10$

(b)

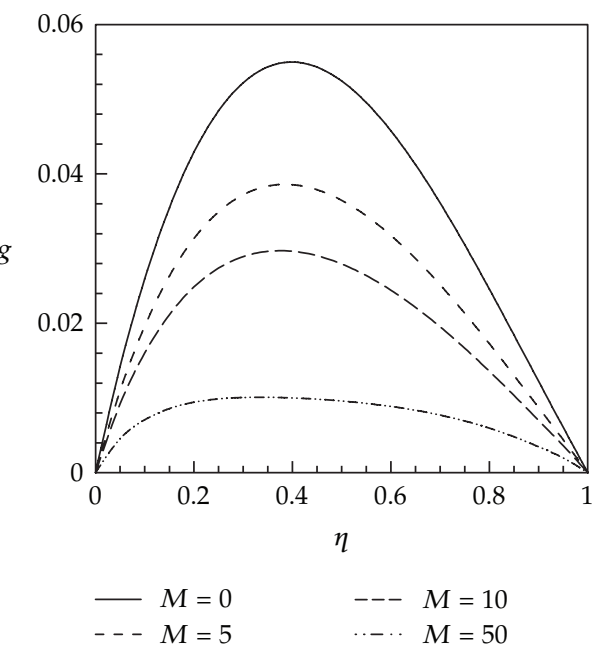

(c)

Figure 2: Velocity components profile (a) $f$, (b) $f^{\prime}$, and (c) $g$ for variable $M$ at $R=2, K_{r}=0.5, \operatorname{Pr}=1$, $\lambda=0.5$, and $\mathrm{Ec}=\mathrm{Ec}_{x}=0.5$.

\section{Analysis of the Homotopy Perturbation Method}

To illustrate the basic ideas of this method, we consider the following equation:

$$
A(u)-f(r)=0 \quad r \in \Omega,
$$

with the boundary condition of

$$
B\left(u, \frac{\partial u}{\partial n}\right)=0 \quad r \in \Gamma
$$




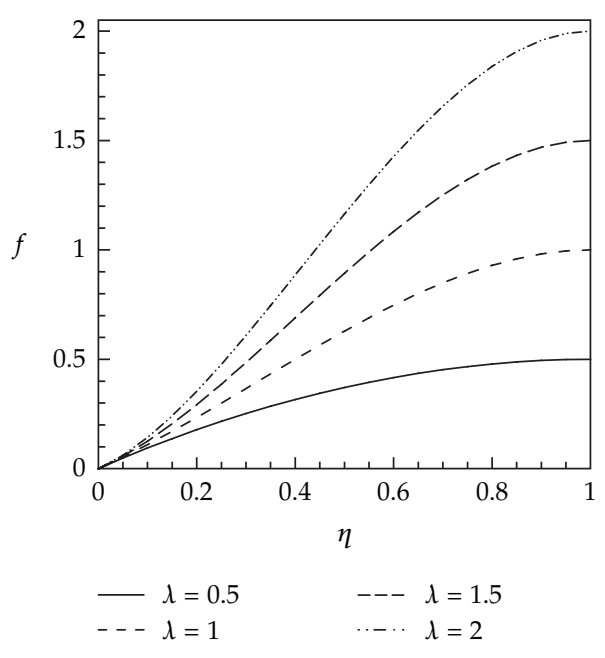

(a)

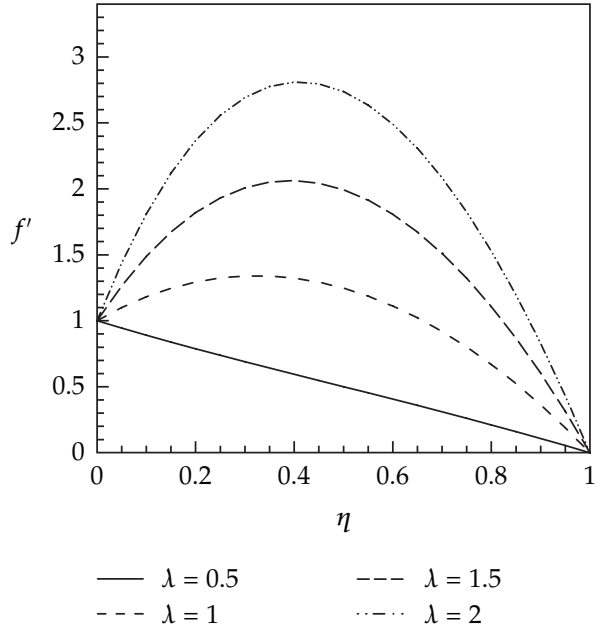

(b)

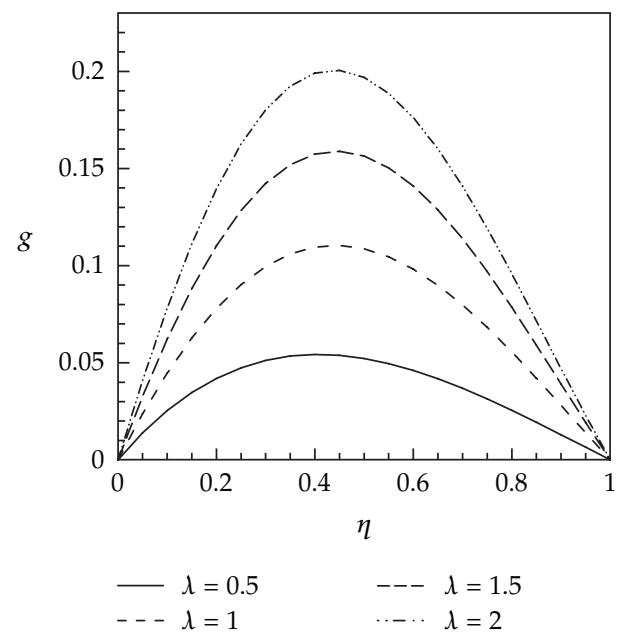

(c)

Figure 3: Velocity components profile (a) $f$, (b) $f^{\prime}$, and (c) $g$ for variable $\lambda$ at $R=2, K_{r}=0.5, M=1, \operatorname{Pr}=1$, and $\mathrm{Ec}=\mathrm{Ec}_{x}=0.5$.

where $A$ is a general differential operator, $B$ is a boundary operator, $f(r)$ is a known analytical function, and $\Gamma$ is the boundary of the domain $\Omega$.

A can be divided into two parts which are $L$ and $N$, where $L$ is linear and $N$ is nonlinear. Equation (4.1) can therefore be rewritten as follows:

$$
L(u)+N(u)-f(r)=0 \quad r \in \Omega .
$$

Homotopy perturbation structure is shown as follows:

$$
H(v, p)=(1-p)\left[L(v)-L\left(u_{0}\right)\right]+p[A(v)-f(r)]=0,
$$

where

$$
\mathcal{v}(r, p): \Omega \times[0,1] \longrightarrow R
$$




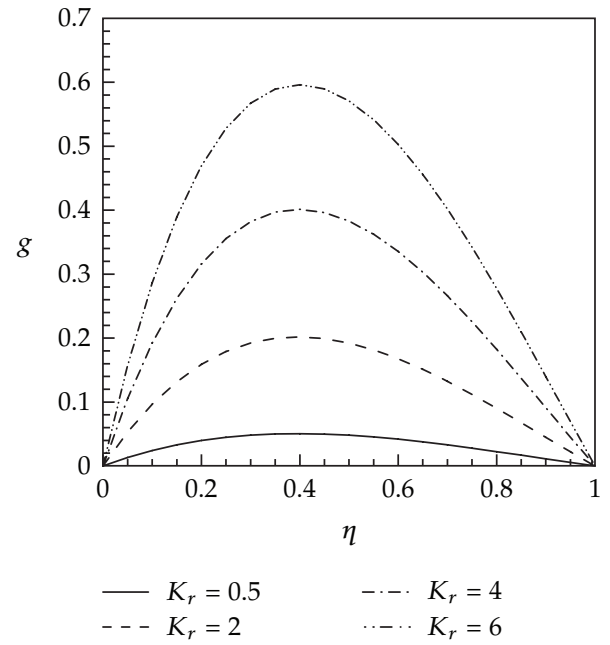

(a)

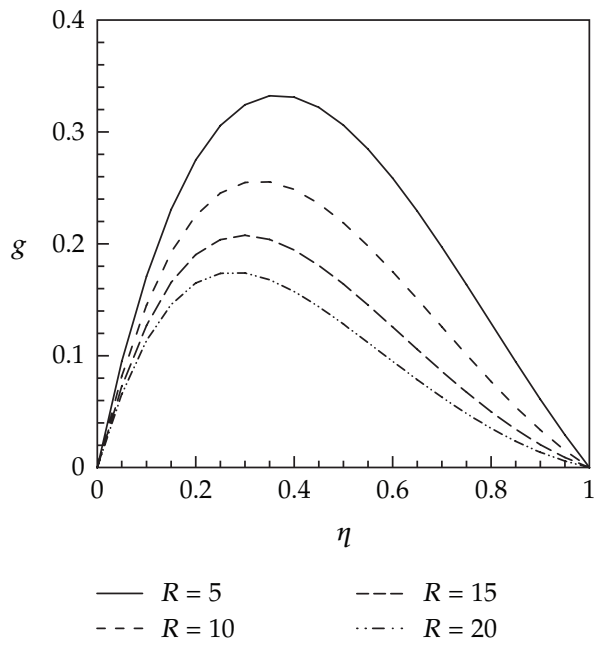

(b)

Figure 4: Velocity components profile $(g)$ for variables $K_{r}$ and $R$ at (a) $R=2, M=1, \lambda=0.5$ and (b) $K_{r}=4$, $M=1, \lambda=0.5$, and $\mathrm{Ec}=\mathrm{Ec}_{x}=0.5$.

In (2.5), $p \in[0,1]$ is an embedding parameter, and $u_{0}$ is the first approximation that satisfies the boundary condition. We can assume that the solution of (4.5) can be written as a power series in $p$, as follows:

$$
v=v_{0}+p v_{1}+p^{2} v_{2}+\cdots
$$

and the best approximation for solution is

$$
u=\lim _{p \rightarrow 1} v=v_{0}+v_{1}+v_{2}+\cdots
$$

\section{Implementation of the Method}

According to the so-called homotopy perturbation method (HPM), we construct a homotopy. Suppose the solution of (4.1) has the following form:

$$
\begin{aligned}
& H(f, p)=(1-p)\left(f^{i v}-f_{0}^{i v}\right)+p\left(f^{i v}-R\left(f^{\prime} f^{\prime \prime}-f f^{\prime \prime}\right)-2 K_{r} g^{\prime}-M f^{\prime \prime}\right)=0, \\
& H(g, p)=(1-p)\left(g^{\prime \prime}-g_{0}^{\prime \prime}\right)+p\left(g^{\prime \prime}-R\left(f^{\prime} g-f g^{\prime}\right)+2 K_{r} f^{\prime}-M g\right)=0, \\
& H(\theta, p)=(1-p)\left(\theta^{\prime \prime}-\theta_{0}^{\prime \prime}\right)+p\left(\theta^{\prime \prime}+\operatorname{Pr}\left[R f \theta^{\prime}+\operatorname{Ec}\left(4 f^{\prime^{2}}+g^{2}\right)+E_{x}\left(f^{\prime \prime 2}+g^{\prime^{2}}\right)\right]\right)=0 .
\end{aligned}
$$




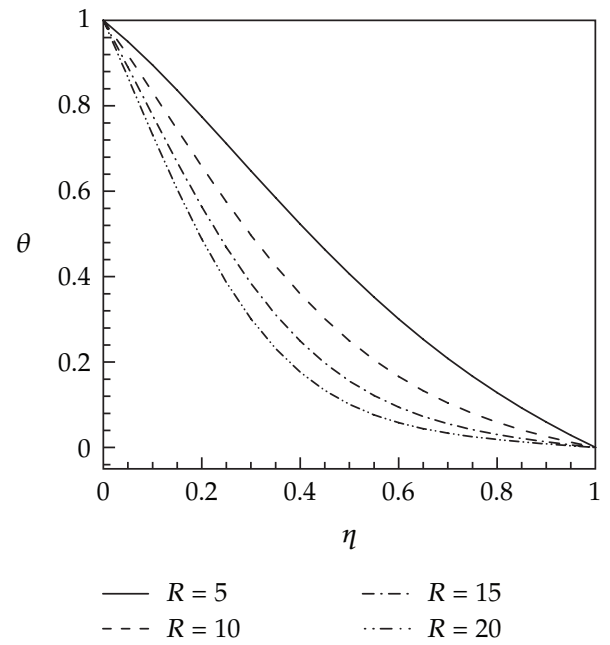

(a)

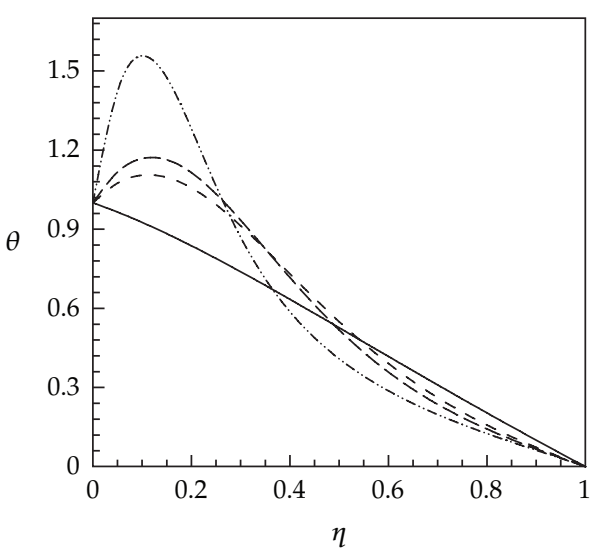

$-\operatorname{Pr}=0.7$

- - $\operatorname{Pr}=7$

$--\operatorname{Pr}=10$

(b)

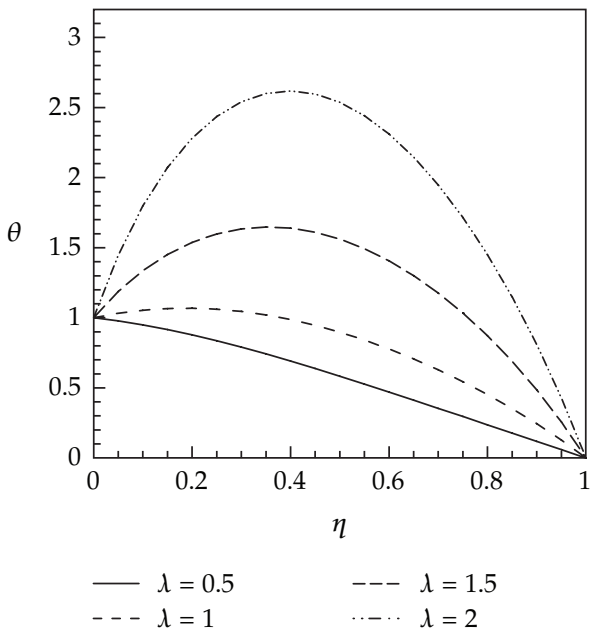

(c)

Figure 5: Temperature profile $(\theta)$ for variables $R$, $\operatorname{Pr}$ and $\lambda$ at $K_{r}=0.5, M=1$, and $\mathrm{Ec}=\mathrm{Ec}_{x}=0.5$ and (a) $\lambda=0.5$ and $\operatorname{Pr}=1$, (b) $R=2$ and $\lambda=0.5$, and (c) $R=2, \operatorname{Pr}=1$.

We consider $f, g, \theta$ as follows:

$$
\begin{aligned}
& f(\eta)=f_{0}(\eta)+p f_{1}(\eta)+\cdots=\sum_{i=0}^{n} p^{i} f_{i}(\eta), \\
& g(\eta)=g_{0}(\eta)+p g_{1}(\eta)+\cdots=\sum_{i=0}^{n} p^{i} g_{i}(\eta), \\
& \theta(\eta)=\theta_{0}(\eta)+p \theta_{1}(\eta)+\cdots=\sum_{i=0}^{n} p^{i} \theta_{i}(\eta) .
\end{aligned}
$$


with substituting $f, g, \theta$ from (5.2) into (5.1) and some simplification and rearranging based on powers of $p$-terms, it can be obtained that

$$
\begin{aligned}
& p^{0}: \\
& f_{0}^{i v}=0, \\
& g_{0}^{\prime \prime}=0, \\
& \theta_{0}^{\prime \prime}=0 .
\end{aligned}
$$

And boundary conditions are

$$
\begin{aligned}
f(0)=0, \quad f^{\prime}(0)=1, & f(1)=1, \quad f^{\prime}(1)=0, \\
g(0)=1, & g^{\prime}(1)=0, \\
\theta(0)=1, & \theta(1)=0,
\end{aligned}
$$

$p^{1}:$

$$
\begin{gathered}
-g_{0}^{\prime}-0.5 f_{0}^{\prime \prime}+0.5 f_{0} f_{0}^{\prime \prime}-0.5 f_{0}^{\prime} f_{0}^{\prime \prime}+f_{1}^{i v}=0, \\
-0.5 f_{0}^{\prime} g_{0}-0.5 g_{0}+g_{1}^{\prime \prime}+0.5 f_{0} g_{0}^{\prime}+f_{0}^{\prime}=0, \\
0.25\left(f_{0}^{\prime \prime}\right)^{2}+0.25\left(g_{0}^{\prime}\right)^{2}+0.25\left(g_{0}\right)^{2}+\theta_{1}^{\prime \prime}+0.25 f_{0} \theta_{1}^{\prime}+\left(f_{0}^{\prime}\right)^{2}=0 .
\end{gathered}
$$

And boundary conditions are

$$
\begin{aligned}
f(0)=0, \quad f^{\prime}(0)=0, & f(1)=0, \quad f^{\prime}(1)=0, \\
g(0)=0, & g^{\prime}(1)=0, \\
\theta(0)=0, & \theta(1)=0,
\end{aligned}
$$

$p^{2}$ :

$$
\begin{gathered}
+0.5 f_{0} f_{1}^{\prime \prime}-g_{0}^{\prime}+0.5 f_{1} f_{0}^{\prime \prime}+0.5 f_{1}^{\prime} f_{0}^{\prime \prime}-0.5 f_{1}^{\prime \prime}+f_{2}^{i v}=0, \\
0.5 f_{1} g_{0}^{\prime}+0.5 f_{0} g_{1}^{\prime}+f_{0}^{\prime}-0.5 g_{1}-0.5 f_{0}^{\prime} g_{1}+g_{2}^{\prime \prime}-0.5 f_{1}^{\prime} g_{0}=0, \\
0.25 f_{0} \theta_{1}^{\prime}+0.25 f_{1} \theta_{0}^{\prime}+0.25\left(f_{0}^{\prime \prime}\right)^{2}+\theta_{2}^{\prime \prime}+2 f_{0}^{\prime} f_{1}^{\prime}+0.5 f_{0}^{\prime \prime} f_{1}^{\prime \prime}+0.5 g_{0} g_{1}+0.5 g_{0}^{\prime} g_{1}^{\prime}=0 .
\end{gathered}
$$

And boundary conditions are

$$
\begin{array}{rlrl}
f(0)=0, & f^{\prime}(0)=0, & f(1)=0, & f^{\prime}(1)=0, \\
g(0)=0, & g^{\prime}(1)=0, \\
\theta(0)=0, & \theta(1)=0 .
\end{array}
$$


By solving (5.3)-(5.5) with boundary conditions for $R=0.5, K_{r}=0.5, M=0.5, \operatorname{Pr}=$ $0.5, \lambda=0.5$, and $\mathrm{Ec}=\mathrm{Ec}_{x}=0.5$, it can be obtained that

$$
\begin{aligned}
f_{0}(\eta)= & -0.5 \eta^{2}+\eta \\
g_{0}(\eta)= & 0 \\
\theta_{0}(\eta)= & -\eta+1 \\
f_{1}(\eta)= & -0.0007 \eta^{6}+0.0083 \eta^{5}-0.0416 \eta^{4}+0.0611 \eta^{3}-0.0270 \eta^{2} \\
g_{1}(\eta)= & 0.1667 \eta^{3}-0.5 \eta^{2}+0.3333 x \\
\theta_{1}(\eta)= & -0.0937 \eta^{4}+0.3750 \eta^{3}-0.6250 \eta^{2}+0.3437 \eta \\
f_{2}(\eta)= & 0.0002 \eta^{8}+0.0010 \eta^{7}-0.0116 \eta^{6}-0.0046 \eta^{5}+0.0116 \eta^{4}-0.0081 \eta^{3}+0.0016 \eta^{2}, \\
g_{2}(\eta)= & 0.0041 \eta^{5}-0.0222 \eta^{4}+0.0368 \eta^{3}-0.0188 \eta \\
\theta_{2}(\eta)= & -0.0001 \eta^{8}+0.0011 \eta^{7}-0.0067 \eta^{6}+0.0180 \eta^{5}-0.0313 \eta^{4}+0.0342 \eta^{3} \\
& -0.0135 \eta^{2}-0.0016 \eta
\end{aligned}
$$

The solution of this equation, when $p \rightarrow 1$, will be as follows:

$$
\begin{aligned}
& f(\eta)=f_{0}(\eta)+f_{1}(\eta)+\cdots+f_{7}(\eta)+f_{8}(\eta) \\
& g(\eta)=g_{0}(\eta)+g_{1}(\eta)+\cdots+g_{7}(\eta)+g_{8}(\eta), \\
& \theta(\eta)=\theta_{0}(\eta)+\theta_{1}(\eta)+\cdots+\theta_{7}(\eta)+\theta_{8}(\eta) .
\end{aligned}
$$

where for $R=0.5, K_{r}=0.5, M=0.5, \operatorname{Pr}=0.5, \lambda=0.5$, and $\mathrm{Ec}=\mathrm{Ec}_{x}=0.5$, the following functions are obtained:

$$
\begin{aligned}
f(\eta)= & -0.0001 \eta^{8}+0.0007 \eta^{7}-0.0012 \eta^{6}+0.0033 \eta^{5}-0.0306 \eta^{4}+0.0537 \eta^{3}-0.5256 \eta^{2}+\eta \\
g(\eta)= & -0.0001 \eta^{8}+0.0002 \eta^{7}+0.0009 \eta^{6}+0.0019 \eta^{5}-0.0203 \eta^{4}+0.2015 \eta^{3}-0.5 \eta^{2}+0.3158 \eta \\
\theta(\eta)= & 0.0001 \eta^{9}-0.0005 \eta^{8}+0.0015 \eta^{7}-0.0093 \eta^{6}+0.0293 \eta^{5}-0.1481 \eta^{4}+0.4322 \eta^{3} \\
& -0.6506 \eta^{2}-0.6546 \eta+1 .
\end{aligned}
$$

\section{Results and Discussion}

The objective of the present study was to apply homotopy perturbation method to obtain an explicit analytic solution of rotating MHD flow and heat transfer of viscous fluid over stretching and porous surface (Figure 1). As can be seen in Table 1, homotopy perturbation method is converged in step 8 , and error has been minimized. There is an acceptable 
Table 1: $\theta(\eta)$ values in different steps of HPM solution at $R=0.5, K_{r}=0.5, M=0.5, \operatorname{Pr}=0.5, \lambda=0.5$, and $\mathrm{Ec}=\mathrm{Ec}_{x}=0.5$.

\begin{tabular}{lccccccccc}
\hline$\eta$ & NM & $n=2$ & $\%$ Error & $n=4$ & $\%$ Error & $n=6$ & $\%$ Error & $n=8$ & $\%$ Error \\
\hline 0 & 1 & 1 & 0 & 1 & 0 & 1 & 0 & 1 & 0 \\
0.1 & 0.928387 & 0.928223 & 0.017678 & 0.928444 & 0.006163 & 0.928449 & 0.006698635 & 0.928449 & 0.00670429 \\
0.2 & 0.846138 & 0.84596 & 0.021041 & 0.846272 & 0.01581 & 0.84628 & 0.016736093 & 0.84628 & 0.016746103 \\
0.3 & 0.755385 & 0.755242 & 0.018984 & 0.755583 & 0.026195 & 0.755592 & 0.027417617 & 0.755592 & 0.027431147 \\
0.4 & 0.657944 & 0.657829 & 0.017493 & 0.658177 & 0.035331 & 0.658186 & 0.036816201 & 0.658187 & 0.036832934 \\
0.5 & 0.555344 & 0.555229 & 0.020556 & 0.555575 & 0.041731 & 0.555585 & 0.043510198 & 0.555585 & 0.043530456 \\
0.6 & 0.44884 & 0.448702 & 0.030858 & 0.449039 & 0.044167 & 0.449048 & 0.046342095 & 0.449048 & 0.046367093 \\
0.7 & 0.339433 & 0.339262 & 0.050375 & 0.339574 & 0.041441 & 0.339583 & 0.044186822 & 0.339583 & 0.044218728 \\
0.8 & 0.227869 & 0.227685 & 0.080907 & 0.227943 & 0.03217 & 0.227951 & 0.035722981 & 0.227951 & 0.035765242 \\
0.9 & 0.114645 & 0.114502 & 0.124586 & 0.114662 & 0.014558 & 0.114667 & 0.019207699 & 0.114667 & 0.019265704 \\
1 & 0 & 0 & 0 & 0 & 0 & 0 & 0 & 0 & 0 \\
\hline
\end{tabular}

Table 2: Comparison between numerical results and HPM solution for $f, g, \theta$ at $R=0.5, K_{r}=0.5, M=0.5$, $\operatorname{Pr}=0.5, \lambda=0.5$, and $\mathrm{Ec}=\mathrm{Ec}_{x}=0.5$.

\begin{tabular}{lccccccccc}
\hline$\eta$ & & $f$ & & & $g$ & & \multicolumn{3}{c}{$\theta$} \\
& NM & HPM & \% Error & NM & HPM & \% Error & NM & HPM & \% Error \\
\hline 0 & 0 & 0 & 0 & 0 & 0 & 0 & 1 & 1 & 0 \\
0.1 & 0.094742 & 0.094794 & 0.054323 & 0.026758 & 0.026778 & 0.073964 & 0.928387 & 0.928449 & 0.006224175 \\
0.2 & 0.179187 & 0.179354 & 0.093254 & 0.044707 & 0.044738 & 0.069201 & 0.846138 & 0.84628 & 0.014169522 \\
0.3 & 0.253603 & 0.253898 & 0.116124 & 0.054988 & 0.055018 & 0.054436 & 0.755385 & 0.755592 & 0.020721081 \\
0.4 & 0.318182 & 0.318574 & 0.123244 & 0.058698 & 0.058716 & 0.030566 & 0.657944 & 0.658187 & 0.024234016 \\
0.5 & 0.373035 & 0.373467 & 0.115934 & 0.056892 & 0.056891 & 0.000929 & 0.555344 & 0.555585 & 0.02417436 \\
0.6 & 0.418197 & 0.418601 & 0.096615 & 0.050587 & 0.050568 & 0.037868 & 0.44884 & 0.449048 & 0.020811422 \\
0.7 & 0.453627 & 0.45394 & 0.068972 & 0.040777 & 0.040746 & 0.077163 & 0.339433 & 0.339583 & 0.015009305 \\
0.8 & 0.479208 & 0.479391 & 0.038258 & 0.028434 & 0.028402 & 0.114496 & 0.227869 & 0.227951 & 0.008149803 \\
0.9 & 0.494751 & 0.49481 & 0.011815 & 0.014521 & 0.0145 & 0.143769 & 0.114645 & 0.114667 & 0.002208717 \\
1 & 0.5 & 0.5 & 0 & 0 & 0 & 0 & 0 & 0 & 0 \\
\hline
\end{tabular}

agreement between the results of numerical solution obtained by four-order Rung-kutte method and differential transformation method as shown in Tables 2 and 3 . In those tables, error is introduced as follows:

$$
\% \text { Error }=\left|\frac{f(\eta)_{\mathrm{NM}}-f(\eta)_{\mathrm{HPM}}}{f(\eta)_{\mathrm{NM}}}\right| \times 100 \text {. }
$$

Figure 2 shows the magnetic field effect on nondimensional velocity component $\left(f, f^{\prime}\right.$, and $g$ ). The decrease of $f$ curve is observed by applying higher magnetic field intensity, and $f^{\prime}$ values increase near stretching sheet and decrease under porous sheet, while at the middle point, these values are constant.

At low Reynolds numbers, the velocity profile exhibits center line symmetry indicating a Poiseuille flow for non-Newtonian fluids. At higher Reynolds numbers, the maximum velocity point is shifted to the streiching wall where shear stress becomes larger as the Reynolds number grows. 
Table 3: Comparison between numerical results and HPM solution for $f, g, \theta$ at $R=0.5, K_{r}=0.5, M=0$, $\operatorname{Pr}=0.5, \lambda=0.5$, and $\mathrm{Ec}_{\mathrm{C}}=\mathrm{Ec}_{x}=0.5$.

\begin{tabular}{lccccccccc}
\hline$\eta$ & & $f$ & & & $g$ & & & \multicolumn{2}{c}{$\theta$} \\
& NM & HPM & \% Error & NM & HPM & \% Error & NM & HPM & \% Error \\
\hline 0 & 0 & 0 & 0 & 0 & 0 & 0 & 1 & 1 & 0 \\
0.1 & 0.094908 & 0.094961 & 0.055277 & 0.027788 & 0.02781 & 0.076047 & 0.9286 & 0.928667 & 0.007196834 \\
0.2 & 0.179709 & 0.179881 & 0.095531 & 0.046609 & 0.046643 & 0.071459 & 0.846601 & 0.846752 & 0.017836439 \\
0.3 & 0.254498 & 0.254803 & 0.119875 & 0.057507 & 0.057539 & 0.056888 & 0.75604 & 0.756261 & 0.029298263 \\
0.4 & 0.319345 & 0.319755 & 0.128301 & 0.061531 & 0.061552 & 0.033084 & 0.658692 & 0.658953 & 0.039612508 \\
0.5 & 0.374292 & 0.374748 & 0.121774 & 0.059736 & 0.059736 & 0.001376 & 0.556078 & 0.556341 & 0.047236899 \\
0.6 & 0.419351 & 0.419781 & 0.102421 & 0.05317 & 0.053151 & 0.036168 & 0.449468 & 0.449697 & 0.050848494 \\
0.7 & 0.454508 & 0.454843 & 0.073797 & 0.04288 & 0.042847 & 0.076493 & 0.339887 & 0.340054 & 0.049140518 \\
0.8 & 0.479718 & 0.479916 & 0.041304 & 0.029902 & 0.029868 & 0.11517 & 0.228122 & 0.228215 & 0.040617504 \\
0.9 & 0.494912 & 0.494976 & 0.012863 & 0.015268 & 0.015246 & 0.14576 & 0.114722 & 0.114749 & 0.023395295 \\
1 & 0.5 & 0.5 & 0 & 0 & 0 & 0 & 0 & 0 & 0
\end{tabular}

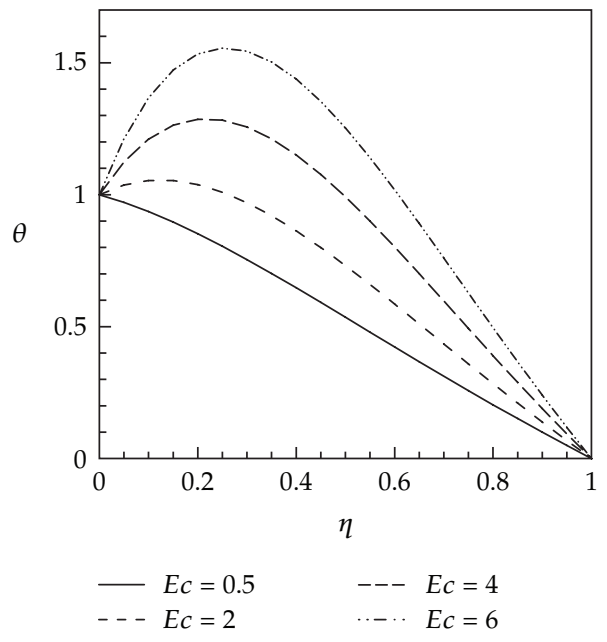

(a)

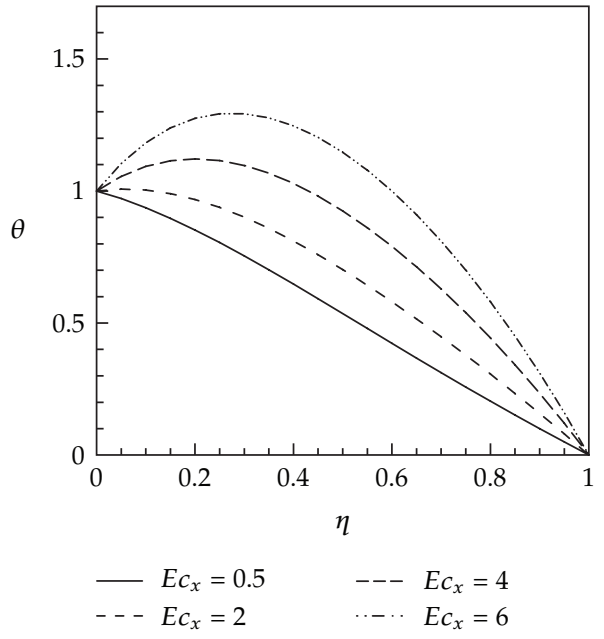

(b)

Figure 6: Temperature profile for variables $\mathrm{Ec}$ and $\mathrm{Ec}_{x}$ at $R=2, K_{r}=0.5, M=1$, $\operatorname{Pr}=1$, and $\lambda=0.5$ and (a) $\mathrm{Ec}_{\mathrm{x}}=0.5$, (b) $\mathrm{Ec}=0.5$.

Blowing velocity parameter $(\lambda)$ has a noticable effect of nondimensional velocity component as shown in Figure 3, which by increasing $\lambda$ profile of $f$ and $f^{\prime}$ becomes nonlinear, and the maximum amount of $f$ and $f^{\prime}$ increases, and velocity component in $x$ direction increases severely.

Also it shows that increasing the blowing velocity parameter leads to $g$ increase, which shows that blowing velocity parameter and magnetic field effects on $g$ are in opposite.

Figure 4 shows that by increasing rotating parameter $\left(K_{r}\right)$, values of transverse velocity component $(g)$ between two sheets increase, and the location of maximum amount of $g$ approaches stretching sheet. Coriolis force has inverse effect on $g$ in comparison with Lorenz force which means that with increasing the rotating parameter transverse $\left(K_{r}\right)$, velocity component between two plates increases as shown in Figure 4 . And it shows that 

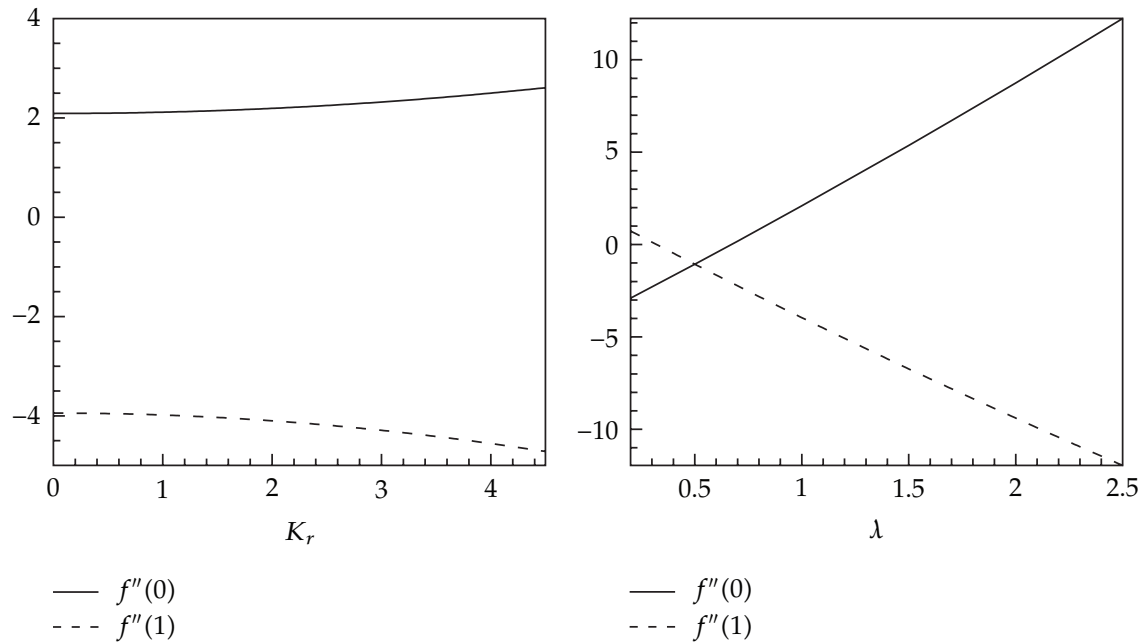

(a)

(b)
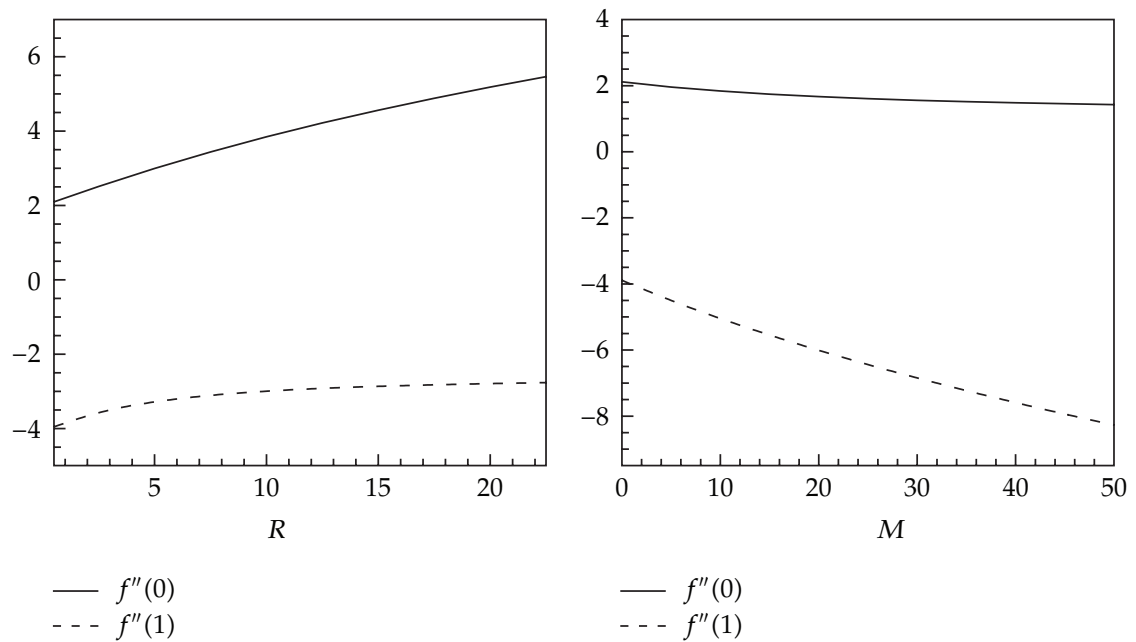

(c)

(d)

Figure 7: The effect of active parameters on skin friction at $\mathrm{Ec}=\mathrm{Ec}_{x}=0.5$ and (a) $R=0.5, M=0.5$, and $\lambda=1$, (b) $R=0.5, K_{r}=0.5$, and $M=0.5$, (c) $K_{r}=0.5, M=0.5$, and $\lambda=1$, (d) $R=0.5, K_{r}=0.5$, and $\lambda=1$.

the viscosity parameter $(R)$ affects $g$ profile similarly to magnetic field; however, with less changes in intensity, also with increasing $R$, the location of maximum amount of $g$ approaching stretching sheet, hat indicates decreasing of boundary layer thickness near stretching plate.

As can be seen in Figure 5, increasing viscosity parameter leads to increasing the curve of temperature profile $(\theta)$ and the decreasing of $\theta$ values, and it can be shown that increasing $\mathrm{Pr}$ in presence of viscous dissipation leads to increasing temperature between two plates. Also increasing temperature between two plates observed, which is caused by increasing this effect, is more sensible near the stretching plate.

The effects of viscous dissipation for which the Eckert number $(\mathrm{Ec})$ and the local Eckert number $\left(\mathrm{Ec}_{x}\right)$ are responsible are shown in Figure 6. It is obvious from the graphs that by 


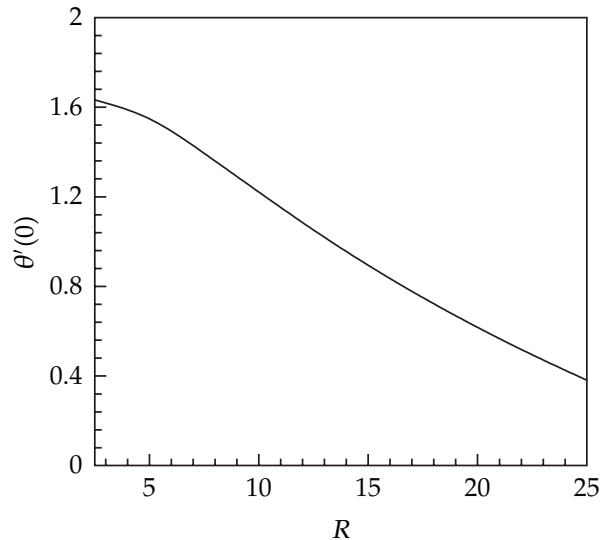

(a)

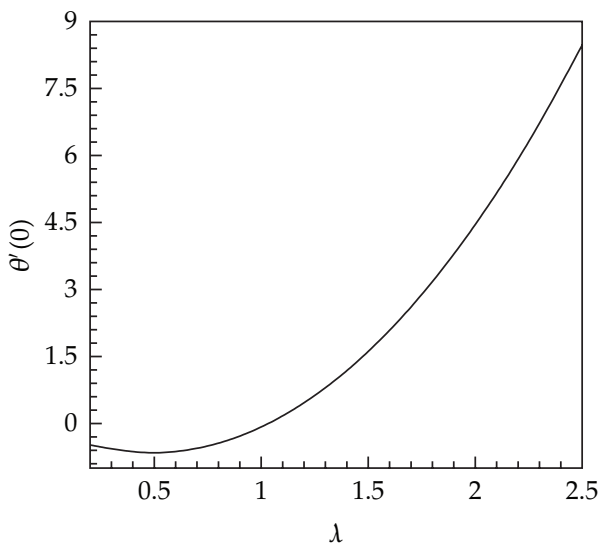

(c)

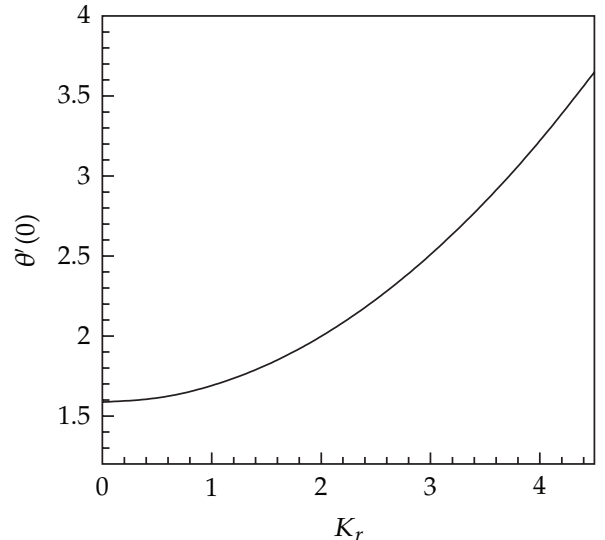

(b)

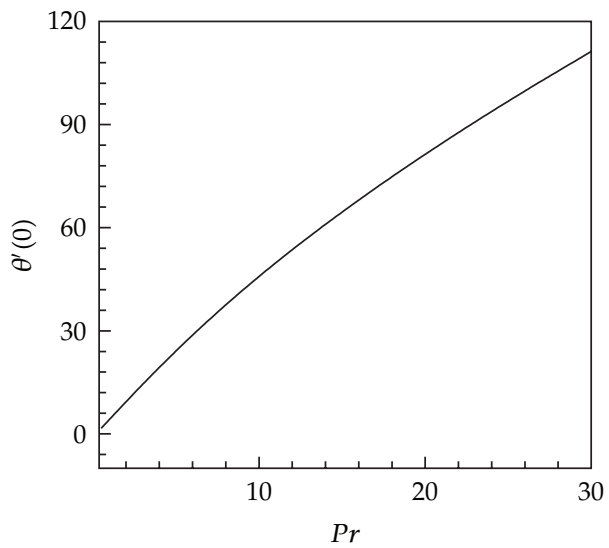

(d)

Figure 8: The effect of active parameters on Nusselt number $\left(N u=\theta^{\prime}(0)\right)$. (a) $K_{r}=0.5, \operatorname{Pr}=0.5, \lambda=1.5$ (b) $R=0.5, \operatorname{Pr}=0.5, \lambda=1.5$ (c) $R=0.5, K_{r}=0.5, \lambda=1.5$ (d) $R=0.5, K_{r}=0.5$, $\operatorname{Pr}=0.5$ and $M=0.5$, $\mathrm{Ec}=\mathrm{Ec}_{x}=0.5$.

increasing $\mathrm{Ec}$ and $\mathrm{Ec}_{x}$, the temperature near the stretching wall increases. This is due to the fact that heat energy is stored in the fluid due to the frictional heating.

In Figure 7, a coefficient of skin friction in stretching plate $\left(f^{\prime \prime}(0)\right)$ and porous plate $\left(f^{\prime \prime}(1)\right)$ is discussed with hanging effective parameters. In stretching plate, with the increase of viscosity parameter, skin friction increases, and increasing rotating parameter leads to a similar effect on skin friction. Applying higher magnetic field intensity leads to skin friction reduction. Increasing blowing velocity parameter leads to skin friction increasing. For porous plate, with the increase of $R$, skin friction decreases, while with $M$ and $K_{r}$ increase, the reduction in skin friction observed; is also with $\lambda$ reduction, skin friction increases.

A coefficient of Nusselt number $\left(\theta^{\prime}(0)\right)$ consulted changes of effective parameters. Increasing the $M$ or $R$ leads to $\mathrm{Nu}$ decreasing, while by increasing $K_{r}, \mathrm{Pr}$, and $\lambda$, the Nusselt number increases, as shown in Figure 8. 


\section{Conclusion}

In this paper, hydromagnetic flow problem between two horizontal plates in a rotating system, where the lower plat is a stretching sheet and the upper is a porous solid plate, has been solved via a sort of analytical method, homotopy perturbation method. Also this problem is solved by a numerical method (the Runge-Kutta method of order 4), and some of the conclusions were summarized as follows:

(a) homotopy perturbation method is a powerful approach for solving nonlinear differential equation such as the discussed problem, and it can be observed that there is a good agreement between the present and numerical results;

(b) presence of magnetic field leads to creating a Lorentz force which causes transverse velocity component reduction between two plates although this force does not have a noticeable effect on temperature profile;

(c) increasing $\operatorname{Pr}$ in presence of viscous dissipation leads to temperature increasing between two plates, while in absence of viscous dissipation, the changes are inverse;

(d) increasing temperature between two plates is due to increasing viscosity parameter or increasing viscous dissipation, whose effect is more sensible near stretching plate;

(e) increasing magnetic parameter or viscosity parameter leads to decreasing $\mathrm{Nu}$, while with increasing the rotation parameter, blowing velocity parameter, and $\mathrm{Pr}$, the Nusselt number increases.

\section{Nomenclature}

$B_{0}: \quad$ Magnetic field $\left(\mathrm{wb} \cdot \mathrm{m}^{-2}\right)$

$M: \quad$ Magnetic parameter

$C_{i}: \quad$ Constant function

$R: \quad$ Viscosity parameter

$K_{r}: \quad$ Rotation parameter

$p^{*}: \quad$ Modified fluid (pressure)

Pr: Prandtl number

Ec: $\quad$ Eckert number

$v_{0}: \quad$ Injection velocity

$U_{\max }$ : Maximum value of velocity

$u, v, w$ : Velocity components along $x, y$, and $z$ axes, respectively.

\section{Greek Symbols}

$v$ : Kinematic viscosity

$\alpha$ : Angle of the channel

$\theta$ : Any angle

$\eta$ : Dimensionless angle

$\rho$ : Fluid density. 


\section{References}

[1] B. K. Dutta, P. Roy, and A. S. Gupta, "Temperature field in flow over a stretching sheet with uniform heat flux," International Communications in Heat and Mass Transfer, vol. 12, no. 1, pp. 89-94, 1985.

[2] H. I. Andersson, J. B. Aarseth, N. Braud, and B. S. Dandapat, "Flow of a power-law fluid film on an unsteady stretching surface," Journal of Non-Newtonian Fluid Mechanics, vol. 62, no. 1, pp. 1-8, 1996.

[3] N. M. Bujurke, S. N. Biradar, and P. S. Hiremath, "Second-order fluid flow past a stretching sheet with heat transfer," Zeitschrift für Angewandte Mathematik und Physik, vol. 38, no. 4, pp. 653-657, 1987.

[4] B. S. Dandapat and A. S. Gupta, "Flow and heat transfer in a viscoelastic fluid over a stretching sheet," International Journal of Non-Linear Mechanics, vol. 24, no. 3, pp. 215-219, 1989.

[5] P. S. Gupta and A. S. Gupta, "Heat and mass transfer on a stretching sheet with suction and blowing," Journal of Chemical and Engineering Data, vol. 55, pp. 744-745, 1977.

[6] B. C. Sakiadis, "Boundary layer behavior on continuous solid flat surfaces," Aiche Journal, vol. 7, pp. 26-28, 1961.

[7] L. E. Erickson, L. T. Fan, and V. G. Fox, "Heat and mass transfer on a moving continuous flat plate with suction or injection," Industrial and Engineering Chemistry Fundamentals, vol. 5, no. 1, pp. 19-25, 1966.

[8] A. Chakrabarti and A. S. Gupta, "Hydromagnetic flow and heat transfer over a stretching sheet," Quarterly of Applied Mathematics, vol. 37, no. 1, pp. 73-78, 1979.

[9] K. Vajravelu and A. Hadjinicolaou, "Convective heat transfer in an electrically conducting fluid at a stretching surface with uniform free stream," International Journal of Engineering Science, vol. 35, no. 13-12, pp. 1237-1244, 1997.

[10] M.Subhas Abel and N. Mahesha, "Heat transfer in MHD viscoelastic fluid flow over a stretching sheet with variable thermal conductivity, non-uniform heat source and radiation," Applied Mathematical Modelling, vol. 32, no. 10, pp. 1965-1983, 2008.

[11] A. K. Borkakoti and A. Bharali, "Hydromagnetic flow and heat transfer between two horizontal plates, the lower plate being a stretching sheet," Quarterly of Applied Mathematics, vol. 41, no. 4, pp. 461-467, 1983.

[12] K. Vajravelu and B. V. R. Kumar, "Analytical and numerical solutions of a coupled non-linear system arising in a three-dimensional rotating flow," International Journal of Non-Linear Mechanics, vol. 39, no. 1, pp. 13-24, 2004.

[13] A. H. Nayfeh, Introduction to Perturbation Techniques, Wiley, New York, NY, USA, 1979.

[14] J.-H. He, "A coupling method of a homotopy technique and a perturbation technique for non-linear problems," International Journal of Non-Linear Mechanics, vol. 35, no. 1, pp. 37-43, 2000.

[15] J. H. He, "Some asymptotic methods for strongly nonlinear equations," International Journal of Modern Physics B, vol. 20, no. 10, pp. 1141-1199, 2006.

[16] M. Jalaal, M. G. Nejad, P. Jalili et al., "Homotopy perturbation method for motion of a spherical solid particle in plane couette fluid flow," Computers and Mathematics with Applications, vol. 61, no. 8, pp. 2267-2270, 2011.

[17] M. Jalaal, D. D. Ganji, and G. Ahmadi, "Analytical investigation on acceleration motion of a vertically falling spherical particle in incompressible Newtonian media," Advanced Powder Technology, vol. 21, no. 3, pp. 298-304, 2010.

[18] A. R. Ghotbi, A. Barari, and D. D. Ganji, "Solving ratio-dependent predator-prey system with constant effort harvesting using homotopy perturbation method," Mathematical Problems in Engineering, Article ID 945420, 8 pages, 2008.

[19] S. M. Moghimi, D. D. Ganji, H. Bararnia, M. Hosseini, and M. Jalaal, “Homotopy perturbation method for nonlinear MHD Jeffery-Hamel problem," Computers and Mathematics with Applications, vol. 61, no. 8, pp. 2213-2216, 2011.

[20] D. D. Ganji, H. R. Ashory Nezhad, and A. Hasanpour, "Effect of variable viscosity and viscous dissipation on the Hagen-Poiseuille flow and entropy generation," Numerical Methods for Partial Differential Equations, vol. 27, no. 3, pp. 529-540, 2011. 


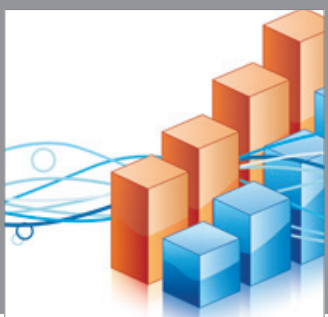

Advances in

Operations Research

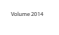

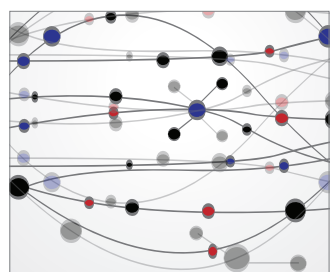

\section{The Scientific} World Journal
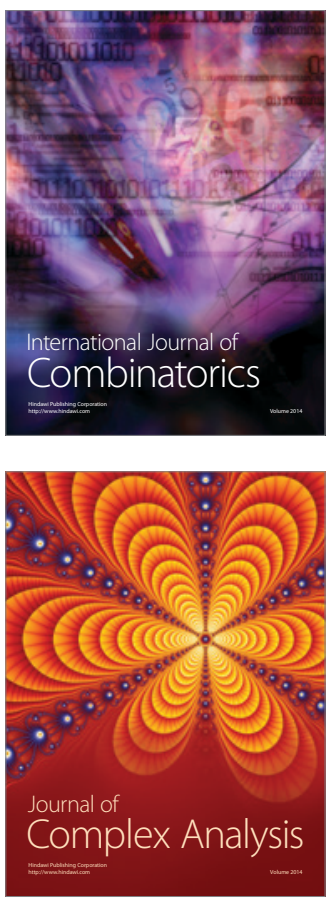

International Journal of

Mathematics and

Mathematical

Sciences
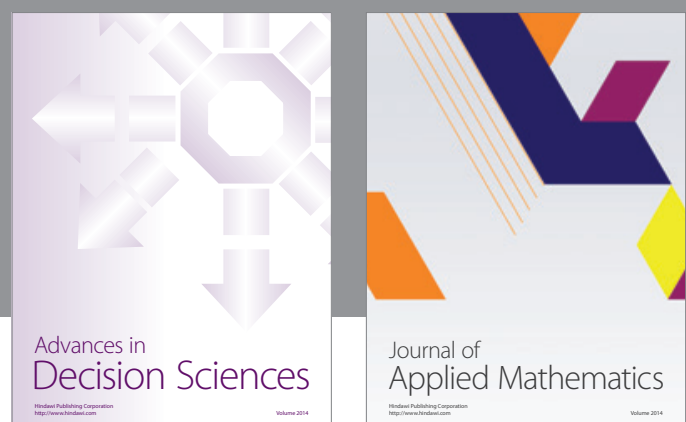

Journal of

Applied Mathematics
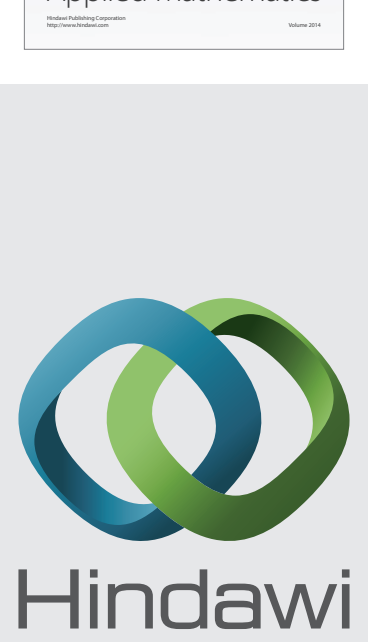

Submit your manuscripts at http://www.hindawi.com
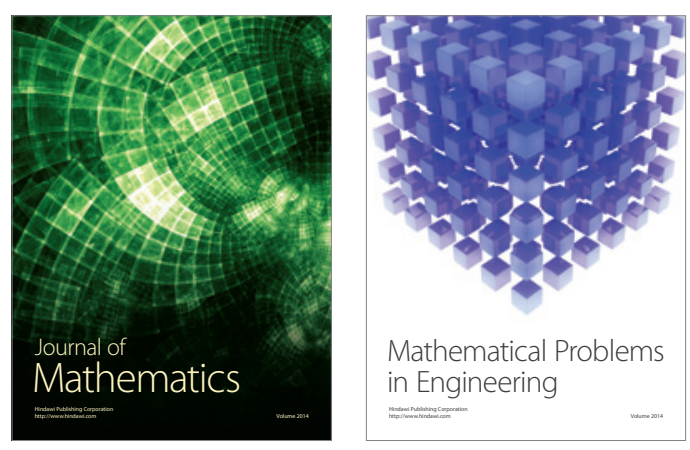

Mathematical Problems in Engineering
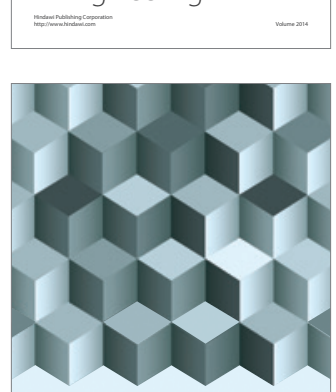

Journal of

Function Spaces
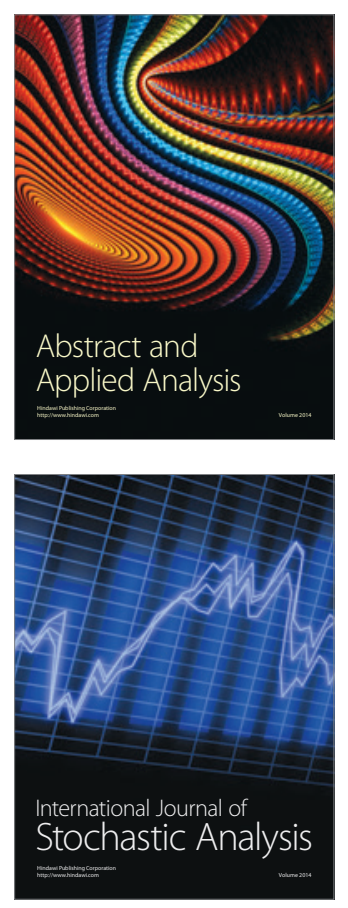

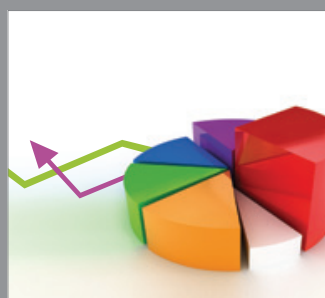

ournal of

Probability and Statistics

Promensencen
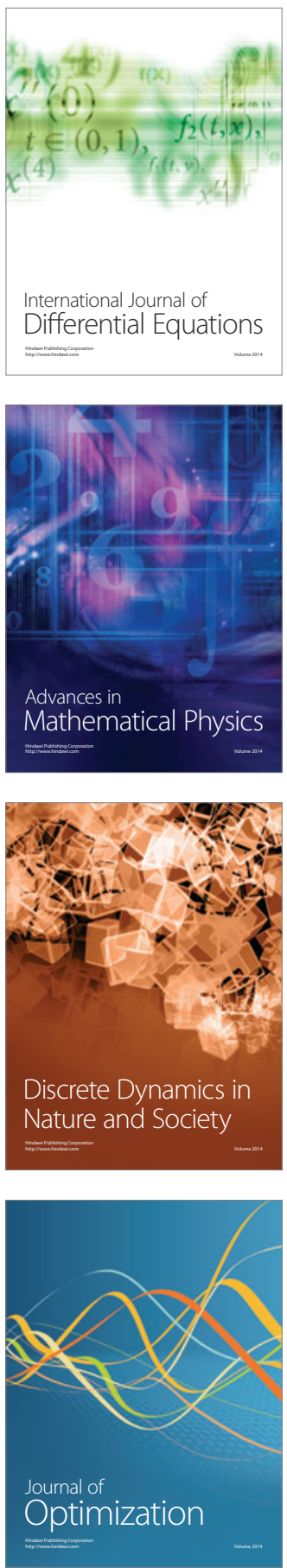